\title{
Segurança Nacional
}

ANTONIO ARRUDA

Desembargador do Tribunal de Justiça do Estado de Mato Grosso. Professor Catedrático da Faculdade de Direito de Cuiabá.

\section{SUMARIO}

1 - Introdução. 2 - Sociedade. 3 - Nação. Interêsses e Aspirações Nacionais. Objetivos Nacionais. Objetivos Nacionais Permanentes e Objetivos $\mathrm{Na}-$ cionais Atuais. 4 - Estado. 5-Poder e Poder Nacional. Elementos do Poder Nacional. Fundamentos e Fatôres. 6 - Ciência Política. Política Nacional. Politica de Desenvolvimento e Política de Segurança.

\section{1 - INTRODUÇÃO}

A Constituição Federal de 1967 trouxe à baila o tema da Segurança Nacional. Alguns dispositivos constitucionais se tornaram particularmente controvertidos, como o artigo 89, que estabelece que "tôda pessoa, natural ou jurídica, é responsável pela Segurança Nacional, nos limites definidos em lei", e o artigo 58, que dá ao Presidente da República a faculdade de expedir decretos, com fôrça de lei, sôbre Segurança Nacional, em casos de urgência ou de interêsse público relevante. Por outro lado, a Lei de Segurança, isto é, o Decreto-lei no 314, de 14-3-1967, agora substituído pelo Decreto-lei n? 898, de 29-9-1969, trouxe algumas definições, ligadas à matéria, e que passaram a ser também extremamente polêmicas. Esta é a razão do presente estudo, que visa a focalizar o
assunto, nos seus variados aspectos, inclusive no que se refere às suas implicações com a legislação brasileira.

tem 0 ponto de partida seria a política nacional, mas esta não Cialm sentido senão quando aplicada a uma comunidade, espenos mente na sua expressão mais ampla, que é o Estado. Isto Origniga a tratar não só do Estado, como das suas formas Originárias - Sociedade e Nação. 


\section{2 - SOCIEDADE}

A tendência inata nos homens é reunirem-se para fins comuns. O homem é um animal sociável, disse Aristóteles, que acrescentou: para viver isolado, o homem teria de ser um bruto ou um deus, o que vale dizer infra-humano ou superhumano. Nas condições em que se acham os homens, a natureza os compele a associarem-se, pois não podem viver sòzinhos, sem leis nem preconceitos. Todos os instintos, bons ou maus, levam os homens à convivência, e esta importa na renúncia parcial da vontade e de impulsos egoístas, em benefício do bem geral.

Històricamente, os homens não aparecem senão em sociedade; até onde chegam as investigações históricas, só encontramos sociedades, mais ou menos perfeitas, incultas ou civilizadas. Daí se conclui que a sociabilidade é fenômeno comum, normal no homem.

A horda, o matriarcado e o patriarcado constituem as matrizes da sociedade.

A primeira forma de convivência foi a horda, isto é, bandos de indivíduos nômades, vivendo da caça e da pesca e em regime de promiscuidade. Com o surgimento da agricultura, os homens passam a reconhecer os vínculos da descendência. É a família que se forma, base da sociedade primitiva e base também da sociedade atual. O vínculo materno é o que surge em primeiro lugar, dado que a maternidade é mais fàcilmente reconhecível que a paternidade. No matriarcado, a mulher-mãe é a figura central. Num terceiro estágio, surge o patriarcado, em que predomina a autoridade do pai, como chefe da família e chefe religioso.

Dessas formas primitivas a sociedade entrou lentamente a progredir, até alcançar os planos atuais de extrema complexidade. Mas, em qualquer dos estágios por que tem passado, a sociedade caracteriza-se pelo fenômeno imperativo da convivência humana e pelo conjunto de circunstâncias gerado pela vida em comum.

Podemos, pois, concluir que:

A sociedade é constituída por determinado grupo humano, que convive sob determinada estrutura de fenômenos sociais, ligados por interêsses comuns, sob o influxo de determinado processo histórico-cultural. 


\section{3 - NAÇÃO}

Como ser social, o homem liga-se visceralmente ao meio em que vive. Pertence à comunidade universal, mas, ao mesmo tempo, ajusta-se melhor ao espaço de terra em que nasceu e aos elementos humanos com os quais convive. A sociabilidade desperta nêle hábitos e aspirações comuns, fortalecendo-lhe idéias e convicções generalizadas, dentre as quais a de que devem ser preservados os benefícios porventura já conseguidos. Sob a ação dessas tendências, surge e cresce progressivamente um sentimento de defesa contra os perigos comuns, assim como um objetivo de aprimorar a vida da comunidade, à qual está ligado por traços de origem étnica, cultural e religiosa, de familia, educação e condições de trabalho.

Sob êsse complexo de instintos, tendências e sentimentos, vai-se estruturando uma comunidade de tradições, costumes, hábitos e outras vigências sociais, assim como de lutas, vocações, interêsses e aspirações comuns - comunidade capaz de zelar pelos valôres alcançados e de conquistar os objetivos colimados. Estabelecem-se, também, gradualmente, vínculos que unem os indivíduos a essa comunidade e a todos os seus demais componentes. Essa comunidade assim formada constitui uma Nação.

A Nação é, pois, um conjunto homogêneo, complexo, mas não caótico. É uma realidade de ordem sociológica, um modo de agrupamento humano. É um fenômeno social resultante de determinado estáglo da evolução da sociedade humana e de certas circunstâncias ocorrentes em sua história.

Escritores, como Renan, introduziram no conceito da NaÇão um sentido poético, cuja expressividade nenhum rigor científico poderia substituir. A Nação é, antes de tudo, como querem êsses escritores, um sentimento ligado às fibras mais intimas do nosso ser: sentimento de solidariedade, que une os indivíduos na crença de um destino comum, no amor das mesmas tradições, na recordação das glórias do passado e no desejo atual de viver em conjunto.

Êsse sentimento traduz-se na consciência nacional, uma espécie de vínculo espiritual, que constitui mesmo o elemento mais forte e indispensável na formação de uma nacionalidade.

Outro elemento que marca e distingue uma Nação é a lingua. $O$ uso de mesmo idioma denota longa convivência, que dá origem a objetivos comuns; além disso, como veículo de 
idéias, a língua cria entre os homens uma afinidade que reforça a consciência nacional.

Outros vínculos, como os de natureza religiosa e étnica, por si sós, não bastam para formarem uma nacionalidade, embora completem os dois acima apontados.

Resumindo, podemos dizer que:

Nação é uma estrutura histórico-cultural, constituída por determinada parcela da humanidade, que vive em determinado espaço de terra, aglutinada sob tradições, costumes, hábitos, linguagem, idéias, crenças, vocações, lutas e vicissitudes comuns, que visa a preservar os valôres alcançados e a realizar os objetivos colimados.

\section{Interêsses e Aspirações. Objetivos Nacionais. Objetivos Nacionais Permanentes \\ e Objetivos Nacionais Atuais.}

As fôrças naturais e básicas de conservação, equilibrio e progresso, forjadas no conjunto de elementos que conformam o espírito de nacionalidade, evolucionam sob um complexo de lutas pela manutenção daquilo que se considera necessário à sobrevivência da comunidade nacional e de anseios pela obtenção de condições existenciais mais dignas para a coletividade, no tempo e no espaço.

As necessidades mais relevantes, tidas como indispensáveis à sobrevivência e à evolução da comunidade nacional, dentro de condições compatíveis com a dignidade humana, caracterizam os Interêsses Nacionais. A projeção dêsses interêsses na consciência da comunidade expressam as Aspiraçöes Nacionais.

Em geral, interêsses e aspirações são coincidentes, mas, nem sempre, isso ocorre. Pode acontecer, às vêzes, que a Nação ainda não se tenha apercebido da conveniência e importância de certos interêsses, a fim de transformá-los em suas próprias aspirações. Há mister então de um processo pedagógico, para que a comunidade nacional eceite tais interêsses e compreenda a necessidade do seu atendimento.

Os interêsses e aspirações nacionais, analisados e interpretados em face de determinada etapa da evolução da comunidade nacional, se traduzem em Objetivos Nacionais, que a 
Nação procura alcançar e preservar, mediante a utilização de todos os meios disponíveis. Assim podemos dizer que:

Objetivos Nacionais são a cristalização dos interêsses e aspirações nacionais, em determinado estágio da evolução da comunidade, cuja conquista e preservação tôda a Nação procura realizar através dos meios de tôda ordem a seu alcance.

Aquêles objetivos nacionais que abrangem interêsses e aspirações vitais, que dizem respeito à independência, soberania, integridade territorial, progresso, instituições políticas básicas etc., e que, por isso mesmo, são relativamente estáveis no tempo e no espaço, caracterizam-se como Objetivos Nacionais Permanentes (ONP).

Os Objetivos Nacionais Permanentes constituem a pedra fundamental de tôda a vida da comunidade nacional e resumem os seus anseios essenciais de conservação, equilíbrio e progresso. Eles devem ser identificados e fixados através de uma análise interpretativa dos interêsses e aspirações nacionais e estarão condicionados pela natureza dos elementos básicos da nacionalidade: a formação biopsíquica e históricocultural do homem, as peculiaridades da terra e a natureza e qualidade das instituições.

A par dêsses objetivos permanentes, devemos considerar também uma gama de outros objetivos, fixados à luz dos interêsses e aspirações nacionais, porém, dentro das limitações impostas pelas possibilidades e circunstâncias do momento. São os Objetivos Nacionais Atuais, que conceituaremos do seguinte modo:

Objetivos Nacionais Atuais são os objetivos que, no quadro de determinada conjuntura, consubstanciam os fins a alcançar pela comunidade nacional, sob a direção do Estado, resultantes de compromissos entre os interêsses e as aspirações nacionais básicas e a capacidade do Poder Nacional.

\section{4 - ESTADO}

A partir do instante em que a Nação, por exigências da Ordem e do progresso, se organiza através de normas disciplinadoras, surge o Estado. A Nação antecede e transcende o Estado, porque se compõe de elementos étnicos, históricos Q culturais, anteriores à organização estatal. Entretanto, é o Estado um imperativo da sobrevivência da Nação, em deter- 
minado estágio de desenvolvimento dos fenômenos sociais. De fato, a necessidade de solucionar problemas de convivência da comunidade nacional obriga à criação de princípios normativos, destinados a reger a vida coletiva e a resguardar a nacionalidade contra reações de entidades adversas. O Estado emerge dêsse complexo ordenatório e coordenador.

O Estado é uma realidade jurídica, é a Nação em têrmos orgânicos. Ou, conforme a definição clássica de Hauriou, é a Nação jurìdicamente organizada. É o órgão que realiza as condições peculiares da fisiologia específica da comunidade nacional; o sistema nervoso do conjunto de instituições nacionais, com função de regê-las. Cabe-lhe dirigir a vida da comunidade à luz de princípios, métodos, normas e ações, segundo uma ordem de natureza jurídica e uma missão de unidade política.

Em suma:

O Estado é a entidade de natureza política que promove a conquista e a manutenção dos Objetivos $\mathrm{Na-}$ cionais, através da utilização ordenada e efetiva dos meios de tôda ordem de que a Nação dispõe.

\section{5 - PODER E PODER NACIONAL}

Ligado também ao nosso tema está o fenômeno do poder, de suma importância e complexidade. Limitar-nos-emos a algumas considerações, necessárias ao entendimento do assunto.

O poder é uma realidade ao mesmo tempo sociológica $e$ jurídica. Sociològicamente, poder é a capacidade ou autoridade para coagir ou dominar os homens, levando-os à obediência, ou obrigando-os a atuarem de certa maneira. Sob o ponto de vista jurídico, o poder é a base de tôda a organização política, e, neste sentido, prende-se ao conceito de Estado. Pode-se conceituar o Estado como o poder organizado para dirigir politicamente a Nação.

Jacques Maritain distingue poder de autoridade. Segundo êste filósofo, autoridade é o direito do comandar, de ser ouvido ou obedecido de outrem; poder é a fôrça de que se dispóe e com auxílio da qual se pode obrigar a outrem a ouvir ou a obedecer. Tôda autoridade, no plano social, necessita completar-se com o poder, sob pena de se tornar vã e ineficaz, entre os homens. Todo poder que não seja expressão da autoridade é ilegítimo: o que importa inicialmente é adquirir a autoridade. 
Analisando a gênese do poder, Max Weber procura explicar os fundamentos das relações de domínio do Estado sôbre os indivíduos, e indica o que êle chama as três formas puras de legitimidade do poder: tradição, carisma e legalidade. Em cada caso, a legitimidade apóia-se em diferente fonte: o poder tradicional, nos costumes santificados; o poder carismático, na confiança que inspiram indivíduos excepcionais; enfim, a autoridade pode provir de um estatuto legal.

Poder significa também capacidade, como salienta $\mathrm{H}$. B. Acton, e, sob êste aspecto, o poder de um homem se calcula em proporção das coisas que êle é capaz de acumular.

O conceito de poder tem envolvido desde a coerção pela fôrça ou pela astúcia, até os processos mais civilizados da obediência pelo consentimento. Nas sociedades primitivas, prevaleceram formas de solução dos conflitos individuais pela vingança, ou seja, pela justiça particular, com assistência do grupo familiar ou gentílico. Posteriormente, houve certo abrandamento, através do duelo, e depois pela composição ou arbitramento, em que a ofensa, ao invés de vingança, era ressarcida.

A formação do Estado coincide justamente com o monopólio do poder e da autoridade. O Estado transforma-se na maior fôrça, dentro da sociedade, porque passou a dispor do poder e da coercibilidade, isto é, do poder a que todos devem obediência - embora esta prerrogativa não singnifique necessàriamente despotismo, porque o Estado deve revestir-se, êle próprio, de uma ordenação legal e justa. Uma das características do poder é a sua instrumentali-
dade: é o instrumento de que se serve o Estado para colimar os seus objetivos. Volvendo à noção de capacidade, podemos afirmar que poder é meio, ou conjunto de meios, aplicados por seus agentes, revestidos de autoridade, para alcançar os fins necessários ou úteis à comunidade. Se visualizarmos, em seu conjunto, todos os meios dispo-
niveis em uma coletividade, teremos o poder de uma Nação ou Poder Nacional. Este poder é constituído da soma e integração, em determinada conjuntura, de todos os meios de que a Nação dispõe.

Podemos, pois, em síntese, dizer que:

PODER NACIONAL é a expressão integrada de meios de tôda ordem de que dispõe efetivamente a Nação, numa época considerada, para promover a conquista e a preservação dos Objetivos Nacionais. 
Estas considerações permitem as seguintes conclusões sôbre a natureza do Poder Nacional:

a) é constituído dos elementos de tôda ordem, abrangendo tôdas as disponibilidades de uma Nação;

b) é exercido através de ações que visam a disciplinar a vida coletiva e a alcançar os Objetivos Nacionais;

c) é limitado no espaço e variável no tempo;

d) atua no âmbito interno e na esfera internacional;

e) apesar de integrado, admite, para fins de análise e planejamento, a subdivisão em formas ou expressões, a saber: política psicossocial, econômica e militar.

\section{Elementos do Poder Nacional -}

\section{Fundamentos e Fatôres}

De maneira global, elemento do Poder Nacional é tudo aquilo que participa de sua composição. Trata-se de elementos dos mais variáveis - recursos humanos, recursos materiais e alguns até bem imponderáveis, com a cultura e o caráter
nacional.

Os autores divergem na classificação dêsses elementos. Podemos agrupá-los em duas ordens: fundamentos e fatôres.

Fundamentos são os elementos que constituem a origem, a base, a fonte do Poder Nacional, elementos sôbre os quais - Poder Nacional fundamentalmente se estrutura e que têm um caráter de relativa permanência no tempo e no espaço.

Fatôres são aquêles elementos que repercutem sôbre os demais, condicionando-os, valorizando-os ou depreciando-os, e, assim, determinam, delimitam o Poder Nacional, dando caráter dinâmico à sua estrutura.

Há nesse conceito uma característica importante: os fundamentos têm relativa estabilidade, enquanto os fatôres são sujeitos a maiores variações.

Vamos exemplificar: o caráter nacional é considerado um fundamento, porque participa, bàsicamente, do Poder Nacional e tem relativa estabilidade no tempo e no espaço; já a moral nacional, ou seja, o maior ou menor grau de resistência de um povo às vicissitudes, é um fator, porque é mais ou menos inspovo às vicissitudes, é um fator, porque é mais ou menos as
tável, o que faz valorizar ou depreciar o Poder, conforme
circunstâncias. 
Nem sempre será fácil caracterizar um elemento essencial do Poder Nacional, seja como fundamento, seja como fator. Esta distinção dependerá, por vêzes, de julgamentos subjetivos. Metodològicamente, devemos procurar esta caracterização, mas o que importa é a necessidade de levar em conta o elemento de que se trata.

A título exemplificativo, vamos enumerar ainda alguns dêsses elementos. Assim, consideramos fundamentos: povo, instituições políticas, população; estrutura social, caráter nacional; recursos naturais, trabalho, capital, emprêsa; as instituifões das Fôrças Armadas, doutrina militar.

São fatôres, segundo nosso entendimento: partidos políticos, cultura política, diplomacia, educação e cultura, opinião pública, o moral nacional, ciência e tecnologia, comércio, moeda, crédito, capacidade do alto comando militar, integração e adestramento das Fôrças Armadas, moral militar.

\section{6 - CIENCIA POLITICA}

É a Política uma ciência? Podemos falar em Ciência Politica? Idêntico problema ocorre com relação às demais Ciências Sociais - a Sociologia, a Economia, o Direito etc., às quais se nega, às vêzes, caráter científico.

A discussão gira em têrmo do conceito de ciência. Esquemàticamente, podemos definir a ciência como um conjunto de conhecimentos certos, ordenados e conexos entre si. Há três requisitos básicos para o acesso ao conhecimento científico: objetivo, método e certeza.

Que a Política, como as demais ciências correlatas, tenha um objetivo determinado e um método adequado, não há dúvida. $A$ argüição maior se refere ao problema da certeza. Constituiria a Política um conjunto de conhecimentos certos? Haverá certeza nos fatos políticos, como a há, p. ex., nos fenômenos físicos?

Aqui é preciso distinguir. A Política e as outras disciplinas Sociais dizem respeito às ações humanas: o material que elas Usam é o material humano e, como tal, vasto, complexo, camCiên mesmo grau de certeza conferido à Matemática ou às Ciências Naturais. A Política não pode chegar à determinação Dolitis exatas, como acontece com outras ciências. As leis politicas, como as leis sociais e éticas, diferem das leis físicas, Os que estas são deduzidas da experiência, abrangem todos fenômenos a que se referem e exprimem o que é, o que 
acontece; enquanto aquelas não abarcam todos os fenômenos, exprimem o que deve ser, e satisfazem-se com uma verdade aproximada da realidade.

Mas, conquanto não haja possibilidade de certeza absoluta nos fenômenos políticos, não se pode negar autonomia à Ciência Política, pelas peculiaridades que apresenta e pela diferenciação natural, oriunda sobretudo dos seus objetivos, da sua finalidade. A Ciência Política, como as ciências sociais, merece esta designação, não só porque o "verdadeiro estudo da humanidade é o homem", como porque essas ciências haurem os seus conhecimentos da observação e da utilização de tôdas as técnicas científicas de mensuração e predição apropriadas às suas esferas de atividades.

Como conceituar a Ciência Política? Em sentido lato, $\cos ^{-}$ tuma-se definir a Ciência Política como o conjunto dos fenômenos sociais de direção da sociedade. Em sentido mais particularizado, podemos conceituar a Ciência Política como a ciência de Estado, ou o ramo das ciências que trata da teoria, organização, govêrno e demais atividades do Estado. Compreende também a análise dos processos que visam a empolgar o poder, dentro dos grupos, ou pelos grupos, organizações ou instituições, mais ou menos independentes do Estado, mas que procuram influenciar a política governamental e orientar as mudanças sociais.

Quanto ao seu objetivo, a Ciência Política abrange um vasto e complexo campo de atividades, aliás ainda não perfeitamente delimitado. No seu contexto, destacam-se assuntos como a origem e o desenvolvimento do Estado; a descrição $e$ análise das estruturas políticas; a técnica da elaboração e da aplicação das leis; a organização e a atuação dos Partidos Políticos e dos grupos de pressão e os estudos sôbre a opinião pública e o processo da comunicação.

Essa é a Política num plano abstrato, mas, como adverte Temístocles Cavalcanti, é preciso distinguir a Ciência Política, que tem preocupação exclusivamente teórica, da Política pròpriamente dita, que se situa mais como arte, como expressão de uma atividade. Vejamos, assim, a Política aplicada à ação operacional, no âmbito dos problemas inerentes a uma Nação.

\section{Política Nacional}

Na ordem instrumental e dinâmica, a Política circunscrevese ao plano do real e do relativo, impôsto pelas circunstâncias. A Política transforma-se, então, na "arte do possível", como a 
definia Bismarck. Dentro dêsse quadro, a Política formula diretrizes e executa ações para dirigir efetivamente a sociedade, ou influir na sua direção.

No plano dinâmico, a Política é a arte de governar um Estado e de dirigir as suas relações internacionais. Sob êste aspecto, a Política se exerce através de ações, devidamente planejadas, no sentido da conquista e manutenção dos Objetivos Nacionais. Realiza-se ela por um conjunto de princípios, diretrizes e normas, a cargo do govêrno, para assegurar as necessidades vitais referentes à conservação, ao equilíbrio, ao progresso e, enfim, à própria sobrevivência da Nação. Éste conjunto constitui a Política Nacional, que podemos sintetizar da seguinte forma:

POLITICA NACIONAL é a ciência e a arte de fixar os Objetivos Nacionais, mediante a interpretação dos interêsses e aspirações da Nação, e orientar a conquista e a preservação daqueles Objetivos.

A Política Nacional compreende dois aspectos básicos: desenvolvimento e segurança. Temos, pois:

Política de Desenvolvimento, integrada na Política Nacional, é o conjunto de normas, diretrizes, planos e programas, que se traduzem em ação dinâmica, capaz de propiciar a sobrevivência nacional. Política de Segurança Nacional, integrada na Política Nacional, é o conjunto de normas, diretrizes, planos e programas, que visam à garantia de consecução ou manutenção dos Objetivos Nacionais. 
